\title{
Dermatologists' Knowledge and Attitude Toward Isotretinoin Ocular Side Effects in Egypt
}

\author{
Mohammed Elshafie (D) \\ Azza Srour (iD ${ }^{2}$ \\ Hussien el-Ansarey (iD ${ }^{2}$ \\ Mostafa Abdel-kader (iD ${ }^{2}$ \\ Ibrahim Kabbash ${ }^{3}$ \\ Mohamed Mashaly ${ }^{4}$ \\ 'Ophthalmology, Faculty of Medicine, \\ KafrELSheikh University, Mansoura, \\ Egypt; ${ }^{2}$ Faculty of Medicine, KafrELSheikh \\ University, KafrELSheikh, Egypt; ${ }^{3}$ Public \\ Health \& Community Medicine, Faculty of \\ Medicine, Tanta University, Tanta, Egypt; \\ ${ }^{4}$ Dermatology, Andrology and STDs, \\ Faculty of Medicine, Port Said University, \\ Mansoura, Egypt
}

\begin{abstract}
Aim: The FDA approved isotretinoin for moderate and severe nodulo-cystic acne, in which it proved effective. However, this misled the dermatologists into using isotretinoin for mild cases as well. This misuse increased the risk of developing adverse effects, especially on the ocular system. These adverse effects vary from mild reversible eye dryness to severe irreversible loss of night vision. Also, it causes contact lens intolerance and corneal ulcer on top. Both ophthalmologists and dermatologists have different perceptions of the drug.

Purpose: To evaluate dermatologists' knowledge and attitude toward ocular adverse effects of isotretinoin in Egypt.

Methods: This cross-sectional study was conducted via an online questionnaire. The questionnaire had three parts: 1) demographic data, 2) knowledge about isotretinoin dry eye disorders, contact lens intolerance, and refractive surgery precautions and 3) dermatologists' management of a case on isotretinoin therapy. We contacted 111 participants from Facebook dermatologists' groups between March and April 2021.
\end{abstract}

Results: We surveyed 111 dermatologists. One hundred and five (94.6\%) reported their knowledge about ocular side effects. One hundred of them (90.1\%) informed their patients about the drug's adverse effects. Eighty-three (74.8\%) reported their knowledge about contact lens intolerance. Forty-one dermatologists (36.9\%) screened their patients for recent refractive surgery before isotretinoin therapy. Nearly, all dermatologists routinely prescribed lubricant eye drops for the patients, and $63(56.8 \%)$ dermatologists sometimes referred their patients to an ophthalmologist. We found an association between knowledge about contact lens intolerance and years of experience $(p=0.012)$. As well, we found that the academic degree of dermatologists is directly proportional with warning patients about ocular side effects $(p=0.003)$ and refractive surgery $(p=0.039)$.

Conclusion: Egyptian dermatologists were knowledgeable about the effects of isotretinoin on eyes with inappropriate clinical practice.

Keywords: awareness, ophthalmic adverse effects, ocular dryness, academic

\section{Introduction}

In 1982, the Food and Drug Administration (FDA) has approved isotretinoin, 13-cis -retinoic acid, as a pharmaceutical preparation for acne vulgaris. ${ }^{1}$ Isotretinoin was prescribed for moderate and severe nodulo-cystic acne that resisted other drug regimens. ${ }^{1}$ Cunliffe et al 1997 recommended isotretinoin for mild cases as well. ${ }^{2}$

Despite proven efficacy, the exact mechanism of isotretinoin is still unclear. ${ }^{3}$ It is suggested that isotretinoin has an apoptotic effect on sebaceous glands, and thus affects lipid production of the skin and other systems with a similar mechanism. ${ }^{3}$

The eyes are one of these systems, where isotretinoin causes reversible atrophy of the meibomian gland. ${ }^{4}$ Fraunfelder et al 2001 classified dry eye disorders as a "certain" side effect for isotretinoin. ${ }^{5}$ They reported 38 cases with decreased
Correspondence: Mohamed Mashaly 35511

Tel +201067123134

Email mohamed.mashaly@med.psu.edu.eg 
tolerance to contact lens. Some of these cases were complicated with a corneal ulcer. ${ }^{5}$ Yildirim et al 2014 stated that corneal biomechanics (diameter and refractive index) did not change; however, changes in the tear film had affected the corneal surface. ${ }^{6}$

Ruiz-Lozano et al 2020 reported photophobia, corneal opacities, keratitis, refractive visual disturbances (day/ night vision disturbances), color vision impairment, and papilledema as rare adverse reactions. ${ }^{4}$

There is a difference between the dermatological and the ophthalmological perceptions of isotretinoin. For dermatologists, it is one of the most effective and available acne treatments. Moreover, its ocular effects are rare, and dryness is reversible after drug stoppage. As a result, many of them may not tell their patients about these effects. For ophthalmologists, however, isotretinoin dryness may complicate a case with contact lens or refractive surgery. Many youths use isotretinoin for acne and prefer contact lens or refractive surgery for a better look. So, many ophthalmologists raise their concerns about drug precautions and side effects.

As far as we know, no studies covered this topic in Egypt. So, we aim to assess Egyptian dermatologists' knowledge and attitude toward ocular adverse reactions and evaluate if the academic degree and years of experience affect this knowledge.

\section{Materials and Methods}

That is a cross-sectional study conducted by a Google Form survey. Our questionnaire has three sections. The first section collects the personal data; including email, age, gender, years of experience, affiliation, academic degree, and city. The second section assesses knowledge about ocular side effects of isotretinoin; including dryness, contact lens intolerance, and refractive surgery precaution. The third section assesses dermatologists' attitude when prescribing isotretinoin; including ophthalmologist referral before the course, lubricant eye drops prescription and warning the patients about possible adverse effects.

The study was approved by the ethical committee at Kafrelsheikh Faculty of Medicine, Kafrelsheikh, Egypt, during March and April 2021. All the participants provided informed consent in accordance with the declaration of Helsinki in the heading section of our google form that reported data could be used for research purposes.

According to official statements from the Egyptian Ministry of Health and Population, 3185 enlisted dermatologists - including those who work abroad. Therefore, we estimated a sample size of 97 dermatologists with 0.05 statistical significance.

We included dermatologists with different academic certifications, and from different Egyptian health institutes.

In Egypt, we have minimal recording data for physicians, making it hard to contact dermatologists via official emails. Instead, we selected our sample randomly from 12 dermatologists' Facebook groups. We conducted dermatologists via private Facebook messenger. Since messages from nonFacebook friends do not appear on the main inbox list, we had to contact 537 dermatologists until we collected 111 responses.

The Google form was linked with Google sheets to collect and organize the data. We analyzed the data using Statistical Package for Social Sciences (SPSS) version 25.0 for windows. We used the exact test for independence with a significance level p-value $<0.05$.

\section{Results}

One hundred eleven consecutive Egyptian dermatologists were surveyed, with a response rate of $20.6 \%$. Of whom, $96(86.5 \%)$ were female and $15(13.5 \%)$ were males (Table 1). Figure 1 shows that Dakahlia governorate has the highest representation $(n=25,22.5 \%)$ then Cairo $(\mathrm{n}=13,11.7 \%)$. Gharbia, Kafr El-Sheikh, and Sharqia shared the same representation $(n=10,9 \%)$.

The participants had an average age of 34.8 years $( \pm 7.1)$ with $8.2( \pm 6.2)$ years of experience. Half of the participants $(n=59,53.2 \%)$ worked in a general hospital. The other half worked in a university hospital, private clinic, teaching hospital, and military hospital by 23 $(20.7 \%), 13(11.7 \%), 10(9 \%)$, and four $(3.6 \%)$, respectively. Only two participants worked in more than one institution (Figure 2).

Table I Gender and Academic Degrees of Participants

\begin{tabular}{|l|c|c|}
\hline Variables & Frequency & Percentage \\
\hline Gender & & \\
Females & 96 & 86.5 \\
Males & 15 & 13.5 \\
\hline Academic degree & & \\
Master & 47 & 42.3 \\
Diploma & 23 & 20.7 \\
MD & 22 & 19.8 \\
PhD & 9 & 8.1 \\
Bachelor & 7 & 6.3 \\
Board & 3 & 2.7 \\
\hline
\end{tabular}




\section{Governorate}

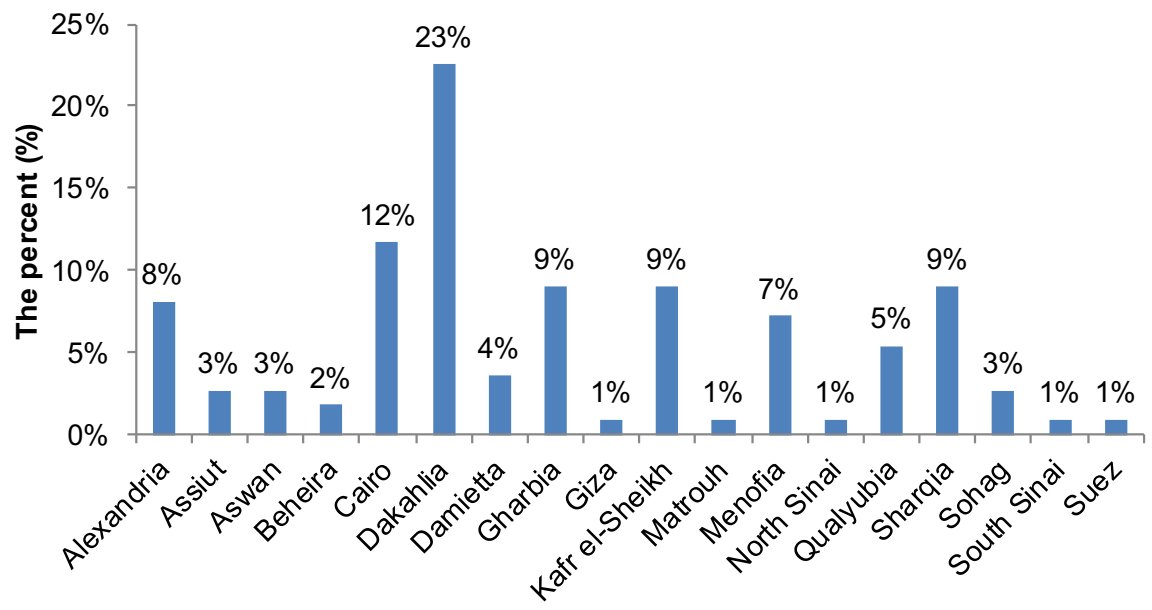

Figure I The percent (\%) of the participants from different Egyptian governorate; indicating Dakahlia as the highest representation.

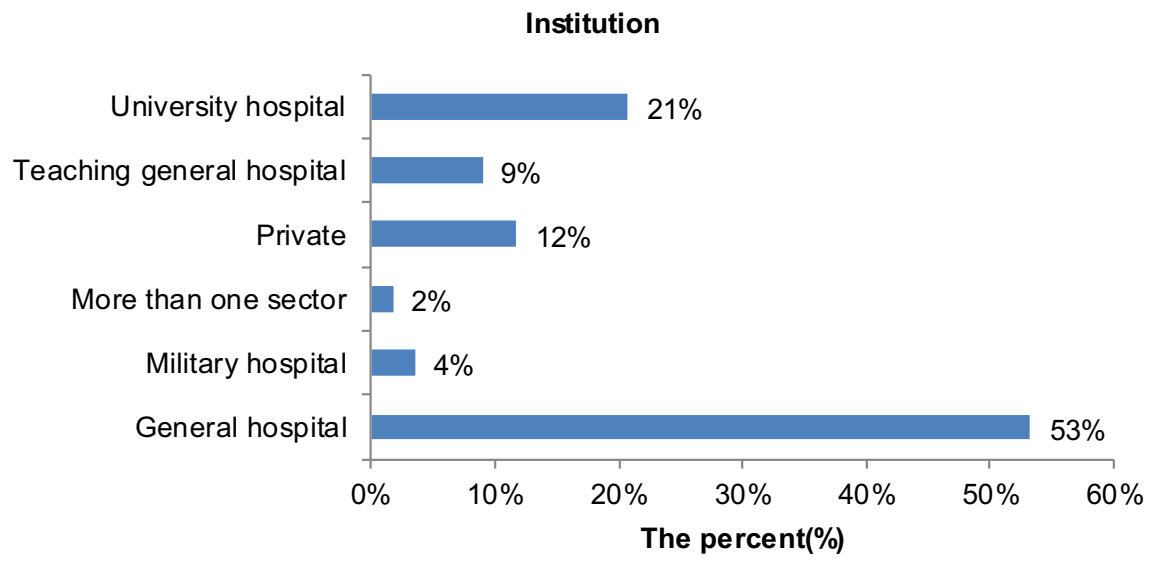

Figure 2 The percent (\%) of the institutions of the participants; indication that most of them are from general hospitals.

Most of them ( $\mathrm{n}=47,42.3 \%)$ had a master degree, Others had diploma $(n=23,20.7 \%)$, MD $(n=22,19.8 \%)$, Ph.D ( $\mathrm{n}=9,8.1 \%)$, bachelor $(\mathrm{n}=7,6.3 \%)$ and board certificates $(\mathrm{n}=3,2.7 \%)$ (Table 1$)$.

Of the sample, 103 (92.8\%) sometimes prescribed isotretinoin alone for moderate to severe nodulo-cystic acne, five $(4.5 \%)$ rarely prescribed it only for a case with primary comedone, and three $(2.7 \%)$ always prescribed the drug for all acne types. For ocular side effects knowledge, 105 (94.6\%) reported their knowledge, and six (5.4\%) dermatologists did not know about them. One hundred (90.1\%) dermatologists informed their patients about ocular dryness and keratitis. Eight (7.2\%) dermatologists sometimes discussed these effects if the patient gave a history of ocular disease. Eighty-three (74.8\%) answered "Yes" they knew about contact lens intolerance associated with isotretinoin usage, and $28(25.2 \%)$ answered "No." Forty-one $(36.9 \%)$ dermatologists always screened recent refractive surgery, 49 (44.1\%) sometimes asked the patient about recent refractive surgery if they doubted, and 21 $(18.9 \%)$ rarely screened their patients. Forty-three (38.7\%) dermatologists warned the patients of refractive surgery for six months after finishing the isotretinoin course. Dermatologists who did not warn their patients or sometimes warn them shared the same percentage $(n=34$, $30.6 \%$ ) (Table 2).

Table 2 shows that about half of dermatologists $(\mathrm{n}=52$, 46.8\%) always prescribed lubricant eye drops for all patients, $31(23.5 \%)$ sometimes prescribed them if the patient had a history of the ocular disease, and 28 (25.2\%) rarely needed them unless the patient returned with symptoms of dry eye. Dermatologists always, sometimes, and 
Table 2 Ocular Side Effects Knowledge, Informing the Patients About Ocular Effects, Recent Refractive Surgery Screening and Warning of Refractive Surgeries for Six Months After Drug Stoppage

\begin{tabular}{|c|c|c|}
\hline Variables & Frequency & Percentage \\
\hline \multicolumn{3}{|l|}{ Ocular side effects knowledge } \\
\hline Yes & 105 & 94.6 \\
\hline No & 6 & 5.4 \\
\hline \multirow{2}{*}{\multicolumn{3}{|c|}{$\begin{array}{l}\text { Informing the patients about } \\
\text { ocular effects }\end{array}$}} \\
\hline & & \\
\hline Yes & 100 & 90.1 \\
\hline Sometimes & 8 & 7.2 \\
\hline No & 3 & 2.7 \\
\hline \multirow{2}{*}{\multicolumn{3}{|c|}{$\begin{array}{l}\text { Contact lenses intolerance } \\
\text { knowledge }\end{array}$}} \\
\hline & & \\
\hline Yes & 83 & 74.8 \\
\hline No & 28 & 25.2 \\
\hline \multicolumn{3}{|l|}{ Refractive surgery screening } \\
\hline Always & 41 & 36.9 \\
\hline Sometimes & 49 & 44.1 \\
\hline Rarely & 21 & 18.9 \\
\hline \multicolumn{3}{|l|}{ Refractive surgery warning } \\
\hline Yes & 43 & 38.7 \\
\hline Sometimes & 34 & 30.6 \\
\hline No & 34 & 30.6 \\
\hline \multicolumn{3}{|l|}{ Ophthalmologist referral } \\
\hline Always & 4 & 3.6 \\
\hline Sometimes & 63 & 58.8 \\
\hline Rarely & 44 & 39.6 \\
\hline \multicolumn{3}{|l|}{ Lubricant eye drops prescription } \\
\hline Always & 52 & 46.8 \\
\hline Sometimes & 31 & 27.9 \\
\hline Rarely & 28 & 25.2 \\
\hline
\end{tabular}

rarely referred the patient to ophthalmologist by $3.6 \%(n=4)$, $58.8 \%(n=63)$, and $39.6 \%(n=44)$; respectively.

We found significant dependence between knowledge about contact lens intolerance and years of experience as a dermatologist ( $p=0.012)$. We found another relationship between the academic degree and informing the patient about ocular adverses $(p=0.003)$, and warning them of the refractive surgery for the upcoming six months $(p=0.039)$. Non-statistically significant data are in Tables 3 and 4.

\section{Discussion}

Nearly all participants knew that isotretinoin causes dry eye, but only $74.8 \%$ reported their knowledge about contact lens intolerance. Using the Chi test for independence, we found a significant association between contact lens intolerance and years of experience $(P=0.012)$. However, there is no statistical significance between ocular adverse effects knowledge and experience years.

That knowledge difference about the two side effects in our study may be due to two main reasons. Firstly, low publication rate of contact lens intolerance compared to dry eye diseases. Fraunfelder et al 2001 reported 38 cases with contact lens intolerance versus 243 patients with ocular dryness on isotretinoin regimen. ${ }^{5}$ Secondly, Egypt is a developing country, and infection issues are popular among the population. Consequently, many dermatologists may accuse bad hygiene of being the reason for intolerance rather than the drug.

Our results for knowledge about dryness and contact lens intolerance were nearly similar to Basheikh et al $2020{ }^{7}$ They reported $97.3 \%$ knowledge about dryness and $89 \%$ knowledge about contact intolerance in Saudi Arabia. ${ }^{7}$

About $18.9 \%$ of dermatologists rarely screened recent refractive surgery, and $30.6 \%$ rarely warned their patients of refractive surgery. Compared to Basheikh et al 2020, $33 \%$ and $44 \%$ rarely screened or warned their patients of refractive surgery, respectively. ${ }^{7}$

Fraunfelder et al 2001 reported dryness as a "certain" side effect of isotretinoin, ${ }^{5}$ and Wilson, 2004 stated that dry eye is a contraindication for LASIK (type of refractive eye surgery). ${ }^{11}$ So, we can hypothesize that isotretinoin is a contraindication for LASIK. ${ }^{11}$ Miles et al 2006 hypothesized the controversial saying that "LASIK is a contraindication for isotretinoin" and recommended a six-month free isotretinoin interval before or after the refractive surgery. ${ }^{8}$

Most of the participants reported they always told their patients about the adverse effects of the drug. Others did not. Sinclair, 2012 accounted that ocular effects are rare and reversible after drug cessation. ${ }^{10}$ Fraunfelder et al 2001 reported some cases with permanent ocular dryness and night blindness during the drug-free interval. ${ }^{5}$ Mollan et al 2006 stated that it is fundamental to warn the patients of the visual adverse effects as it may influence their career. ${ }^{9}$ They are concerned that night vision affection potentially increases the risk of dangerous incidences or crashes. ${ }^{9}$

Using the Chi test for independence, a significant association was found between the academic degree and informing the patients about the adverse effects $(p=0.003)$. Also, there was an association between the academic degree and refractive surgery warning ( $p=0.039)$. We believe that a high academic degree is associated with more reads and analysis, and more confidence to warn the patients accordingly. Moreover, in 
Table 3 Relationship Between Dermatologists' Academic Degree and Their Knowledge and Performance About Isotretinoin Therapy

\begin{tabular}{|c|c|c|c|c|c|c|c|}
\hline \multirow[t]{3}{*}{ Variables } & \multicolumn{6}{|c|}{ Academic Degree } & \multirow[t]{3}{*}{$P$ value } \\
\hline & \multicolumn{2}{|c|}{ Bachelor/Board $(n=10)$} & \multicolumn{2}{|c|}{ Diploma/M.Sc. $(n=70)$} & \multicolumn{2}{|c|}{ MD/PhD (n=3I) } & \\
\hline & $\mathbf{n}$ & $\%$ & $\mathbf{n}$ & $\%$ & $\mathbf{n}$ & $\%$ & \\
\hline Isotretinoin prescription & & & & & & & 0.636 \\
\hline Always & 0 & 0.0 & 3 & 4.3 & 0 & 0.0 & \\
\hline Sometimes & 10 & 100.0 & 64 & 91.4 & 29 & 93.5 & \\
\hline Rarely & 0 & 0.0 & 3 & 4.3 & 2 & 6.5 & \\
\hline Ocular side effects knowledge & & & & & & & 0.099 \\
\hline Yes & 8 & 80.0 & 67 & 95.7 & 30 & 69.8 & \\
\hline No & 2 & 20.0 & 3 & 4.3 & 1 & 3.2 & \\
\hline Refractive surgery screening & & & & & & & 0.350 \\
\hline Always & 1 & 10.0 & 26 & 37.2 & 14 & 45.2 & \\
\hline Sometimes & 6 & 60.0 & 32 & 45.7 & 11 & 35.5 & \\
\hline Rarely & 3 & 30.0 & 12 & 17.1 & 6 & 19.3 & \\
\hline Refractive surgery warning & & & & & & & $0.039 *$ \\
\hline Yes & I & 10.0 & 32 & 45.7 & 10 & 32.2 & \\
\hline Sometimes & 2 & 20.0 & 20 & 28.6 & 12 & 38.7 & \\
\hline No & 7 & 70.0 & 18 & 25.7 & 9 & 29.1 & \\
\hline Contact lenses intolerance knowledge & & & & & & & 0.421 \\
\hline Yes & 6 & 60.0 & 52 & 74.3 & 25 & 80.7 & \\
\hline No & 4 & 40.0 & 18 & 25.7 & 6 & 19.3 & \\
\hline Patients informed about adverse effects & & & & & & & $0.003 *$ \\
\hline Yes & 8 & 80.0 & 66 & 94.3 & 26 & 83.9 & \\
\hline Sometimes & 0 & 0.0 & 4 & 5.7 & 4 & 12.9 & \\
\hline No & 2 & 20.0 & 0 & 0.0 & 1 & 3.2 & \\
\hline Ophthalmologist referral & & & & & & & 0.767 \\
\hline Always & 0 & 0.0 & 2 & 2.9 & 2 & 6.4 & \\
\hline Sometimes & 5 & 50.0 & 40 & 57.1 & 18 & 58.1 & \\
\hline Rarely & 5 & 50.0 & 28 & 40.0 & 11 & 35.5 & \\
\hline Lubricant eye drops prescription & & & & & & & 0.721 \\
\hline Always & 3 & 30.0 & 32 & 45.7 & 17 & 54.8 & \\
\hline Sometimes & 4 & 40.0 & 20 & 28.6 & 7 & 22.6 & \\
\hline Rarely & 3 & 30.0 & 18 & 25.7 & 7 & 22.6 & \\
\hline
\end{tabular}

Note: *Significant.

Egypt, a high academic degree of the doctor is associated with more respect from the patients. We assume that doctors' confidence and patients' respectful attitude help dermatologists inform their patients about the ocular adverse effects and warn them of refractive surgery.

Dermatologists routinely prescribed lubricants with any degree of dryness. It is an acceptable practice. Half of the dermatologists rarely referred their patients to an ophthalmologist. We cannot reject that ocular effects are mild and reversible after the drug stop. However, we share the same concerns of Fraunfelder et al 2001 and Mollan et al 2006 about permanent night vision blindness and ocular dryness, especially; with high doses. ${ }^{5,9,12}$ It is essential to know when to stop the drug and consult the ophthalmologist.

All other non-significant Chi tests are a good indicator that information about the adverse effects is basically available and easily accessible. Tables 3 and 4

\section{Recommendations}

Ask about the patient's career: Consulting ophthalmologists is recommended for patients who depend on night vision for their jobs. 
Table 4 Relationship Between Dermatologists' Years of Experience and Their Knowledge and Performance About Isotretinoin Therapy

\begin{tabular}{|c|c|c|c|c|c|c|c|}
\hline \multirow[t]{3}{*}{ Variables } & \multicolumn{6}{|c|}{ Years of Experience } & \multirow[t]{3}{*}{$P$ value } \\
\hline & \multicolumn{2}{|c|}{$0-10(n=85)$} & \multicolumn{2}{|c|}{$11-20(n=19)$} & \multicolumn{2}{|c|}{$21-30(n=7)$} & \\
\hline & $\mathbf{n}$ & $\%$ & $\mathbf{n}$ & $\%$ & $\mathbf{n}$ & $\%$ & \\
\hline Isotretinoin prescription & & & & & & & 0.858 \\
\hline Always & 3 & 3.5 & 0 & 0.0 & 0 & 0.0 & \\
\hline Sometimes & 78 & 91.8 & 18 & 94.7 & 7 & 100.0 & \\
\hline Rarely & 4 & 4.7 & I & 5.3 & 0 & 0.0 & \\
\hline Ocular side effects knowledge & & & & & & & 0.803 \\
\hline Yes & 80 & 94.1 & 18 & 94.7 & 7 & 100.0 & \\
\hline No & 5 & 5.9 & I & 5.3 & 0 & 0.0 & \\
\hline Refractive surgery screening & & & & & & & 0.591 \\
\hline Always & 29 & 34.1 & 8 & 42.1 & 4 & 57.1 & \\
\hline Sometimes & 39 & 45.9 & 7 & 36.8 & 3 & 42.9 & \\
\hline Rarely & 17 & 20.0 & 4 & 21.1 & 0 & 0.0 & \\
\hline Refractive surgery warning & & & & & & & 0.329 \\
\hline Yes & 30 & 35.3 & 8 & 42.1 & 5 & 71.4 & \\
\hline Sometimes & 29 & 34.1 & 4 & 21.1 & 1 & 14.3 & \\
\hline No & 26 & 30.6 & 7 & 36.8 & I & 14.3 & \\
\hline Contact lenses intolerance knowledge & & & & & & & $0.012^{*}$ \\
\hline Yes & 58 & 68.2 & 19 & 100.0 & 6 & 85.7 & \\
\hline No & 27 & 31.8 & 0 & 0.0 & I & 14.3 & \\
\hline Patients informed about adverse effects & & & & & & & 0.775 \\
\hline Yes & 78 & 91.8 & 16 & 84.2 & 6 & 85.7 & \\
\hline Sometimes & 5 & 5.9 & 2 & 10.5 & 1 & 14.3 & \\
\hline No & 2 & 2.3 & I & 5.3 & 0 & 0.0 & \\
\hline Ophthalmologist referral & & & & & & & 0.810 \\
\hline Always & 3 & 3.5 & I & 5.3 & 0 & 0.0 & \\
\hline Sometimes & 46 & 54.1 & 12 & 63.1 & 5 & 71.4 & \\
\hline Rarely & 36 & 42.4 & 6 & 31.6 & 2 & 28.6 & \\
\hline Lubricant eye drops prescription & & & & & & & 0.245 \\
\hline Always & 39 & 45.9 & 7 & 36.8 & 6 & 85.7 & \\
\hline Sometimes & 25 & 29.4 & 6 & 31.6 & 0 & 0.0 & \\
\hline Rarely & 21 & 24.7 & 6 & 31.6 & I & 14.3 & \\
\hline
\end{tabular}

Note: *Significant.

Be aware to contact lens intolerance cause: Whether it is due to isotretinoin or ocular infection.

Screen refractive surgery in adolescents: The most common age for refractive surgery is the adolescence age. We recommend an ophthalmologist referral before starting isotretinoin therapy if the patient has a recent refractive surgery.

Stop the drug after an ophthalmologist consult: If there is a marked drop in the night vision or severe dryness manifestations, refer your patient to an ophthalmologist and respect his consultation.
Lubricant eye drops prescription: Prescribe eye drops with high concentration of sodium hyaluronate to be applied from the first day.

\section{Limitations}

The question "Do you prescribe isotretinoin alone?" was unidentified. We should have specified it as oral or topical. Also, we should have specified the dose. During analysis, we discovered that we had two correct answers for that question: "Sometimes; for severe, moderate nodulo-cystic 
acne" and "Rarely; for primary comedonal acne." We reported its results without interpretation. Despite misdesigning it, that question aimed to assess dermatologists' compliance with the updated version of the American Academy of Dermatology guidelines for acne treatment. We recommend conducting more observational studies with larger sample size and higher response rate.

\section{Conclusion}

Nearly all dermatologists knew about isotretinoinassociated dryness; prescribed lubricant eye drops routinely. Three-fourth of them knew about associated contact lens intolerance with positive dependence between this knowledge and their years of experience as a dermatologist. Less than half screened refractive surgery and warned their patients of having one for six months after drug stoppage. Nearly all participants informed their patients about the ocular adverse effects of the drug, and $67 \%$ of them referred the patient to an ophthalmologist for a checkup. These findings demonstrate good knowledge of Egyptian dermatologists about ocular side effects. However, they have a poor attitude toward the appropriate clinical practice, especially with refractive surgery cases.

\section{Acknowledgments}

We appreciate our colleagues who helped us during data collection and supported us: Abdelrahman Atef Ghalwash, Ahmed Shaher Elsharnouby, and Reem Fawzy Suliman.

\section{Disclosure}

The authors report no conflicts of interest in this work.

\section{References}

1. Vallerand IA, Lewinson RT, Farris MS, et al. Efficacy and adverse events of oral isotretinoin for acne: a systematic review. $\mathrm{Br}$ J Dermatol. 2018;178(1):76-85. doi:10.1111/bjd.15668

2. Cunliffe WJ, Van de Kerkhaf PC, Caputo R, et al. Roaccutane treatment guidelines: results of an international survey. Dermatology. 1997;194(4):351-357. doi:10.1159/000246134

3. Melnik BC. Apoptosis may explain the pharmacological mode of action and adverse effects of Isotretinoin, including teratogenicity. Acta Derm Venereol. 2017;97(2):173-181. doi:10.2340/000155552535

4. Ruiz-Lozano RE, Hernández Camarena JC, Garza-Garza LA, Bustamante-Arias A, ColoradoZavala MF, Cardenas-de la Garza JA. Isotretinoin and the eye: a review for the dermatologist. Dermatol Ther. 2020;33(6):e14029. doi:10.1111/dth.14029

5. Fraunfelder FT, Fraunfelder FW, Edwards R. Ocular side effects possibly associated with isotretinoin usage. Am J Ophthalmol. 2001;132(3):299-305. doi:10.1016/S0002-9394(01)01024-8

6. Yildirim Y, Olcucu O, Agca A, et al. Evaluation of corneal topography and biomechanical parameters after use of systemic isotretinoin in acne vulgaris. $J$ Ophthalmol. 2014;2014:701361. doi:10.1155/ 2014/701361

7. Basheikh A, Alattas A, Alshareef R, Bamahfouz A. Dermatologists' knowledge and attitudes toward dry eye disease, refractive surgery, and contact lens when prescribing isotretinoin in Saudi Arabia. Clin Ophthalmol. 2020;14:4519-4522. doi:10.2147/OPTH.S292569

8. Miles S, McGlathery W, Abernathie B. The importance of screening for laser-assisted in situ keratomileusis operation (LASIK) before prescribing isotretinoin. $J$ Am Acad Dermatol. 2006;54(1):180-181. doi:10.1016/j.jaad.2005.08.060

9. Mollan SP, Woodcock M, Siddiqi R, Huntbach J, Good P, Scott RAH. Does use of isotretinoin rule out a career in flying? Br J Ophthalmol. 2006;90(8):957-959. doi:10.1136/bjo.2006.092833

10. Sinclair W. The rational use of systemic isotretinoin in acne: a call for moderation. S Afr Med J. 2012;102(5):282-284. doi:10.7196/ samj. 5310

11. Wilson SE. Use of lasers for vision correction of nearsightedness and farsightedness. $N$ Engl J Med. 2004;351(5):470-475. doi:10.1056/ NEJMcp033210

12. Cumurcu T, Sezer E, Kilic R, Bulut Y. Comparison of dose-related ocular side effects during systemic isotretinoin administration. Eur $J \quad$ Ophthalmol. 2009;19(2):196-200. doi:10.1177/1120672109 01900204
Clinical, Cosmetic and Investigational Dermatology

Publish your work in this journal

Clinical, Cosmetic and Investigational Dermatology is an international, peer-reviewed, open access, online journal that focuses on the latest clinical and experimental research in all aspects of skin disease and cosmetic interventions. This journal is indexed on CAS.
The manuscript management system is completely online and includes a very quick and fair peer-review system, which is all easy to use. Visit http://www.dovepress.com/testimonials.php to read real quotes from published authors. 